\title{
Role of Immunity Boosting Nutritional Foods and COVID-19
}

\section{Mishra P*, Mohapatra AK and Maharana S}

IMS and SUM Hospital, SOA University, Odisha, India

*Corresponding Author: Mishra P, IMS and SUM Hospital, SOA University, Odisha, India.
Received: May 30, 2020

Published: August 11, 2020

(C) All rights are reserved by Mishra P., et al.

\begin{abstract}
"Health is wealth". Keeping oneself healthy is one of the concerns today. Depending on the climate, regions, places many people eat their local foods and keep themselves fit. Some do yoga and exercise along with the food. But it has been seen that a balanced nutritional diet is the main cause of the keeping a person fit. Depending on the diseases proper foods are advised.

Today WHO has declared the CoVID-19 cases as pandemic. The whole world is panic now. In this situation making your immunity through your daily available food is one of the important issues. Of course side by side breathing exercise is advised.

In this report, Nutrition related issues in relations to immunity to avoid infection of COVID -19 is discussed, besides maintaining social distancing among people, use of mask and repeated hand washing.
\end{abstract}

Keywords: COVID-19; Immunity; Coronavirus

\section{Introduction}

The name "coronavirus" is derived from Latin corona, means "crown" or "wreath" $[3,4]$. Coronaviruses are group of related viruses that cause diseases in mammals and birds. They cause upper respiratory tract infection in case of humans. Human coronavirus was first discovered in the late 1960s [1]. The earliest ones discovered in chickens named 'infectious bronchitis virus and two in human patients with the common cold named 'human coronavirus 229E' and 'human coronavirus OC43' [2]. Later in 2003 SARS-CoV was identified, in 2004 HCoV NL63, in 2005 HKU1, in 2012 MERSCoV and in 2019 SARS-CoV-2 formerly known as 2019-n CoV. The coronavirus came from a seafood and meat market in Wuhan, China, in December 2019 according to the American Academy of Family Physicians (familydoctor.org).

\section{Causes}

The main cause of coronavirus (COVID-19) infection is known to happen by close contact between humans. If the droplets are coughed or sneezed by an infected person, these are passed through the airways or touched by a healthy person who can touch its mouth, eye, nose or ears by which the virus will be transmitted.

It has an adherence property with many metals and other usable materials [5]. Table 1 gives the details of the same.

Besides respiratory tract it also affects the gastrointestinal organs [5]. The virus has been found in faeces of hospitalized patients. They found more in anal swab positives than oral swab positives in the later stage of infection [6]. The virus was found to stay in faeces from 1 to 2 days [5]. Stability of SARS Coronavirus in Human Specimens and Environment and Its Sensitivity to Heating and UV Irradiation has been reported by Duan., et al. [7].

\section{Signs and symptoms}

Fever, cough, fatigue, shortness of breath [8-10] are the main causes of this infection. Emergency symptoms are difficult breathing, persistent chest pain or pressure, confusion, difficulty waking and bluish face or lips [11]. Less common symptoms like upper respiratory symptoms like sneezing, runny nose or sore throat 


\begin{tabular}{|c|c|}
\hline Metal/other materials & Time, Covid-19 stays (h) \\
\hline Stainless steels & 72 \\
\hline copper, & 4 \\
\hline Cardboards & 24 \\
\hline Plastic board & 24 \\
\hline
\end{tabular}

Table 1: Duration (COVID-19 can stay in different material).

may be seen. Nausea, vomiting and diarrhea have been observed in varying percentages [12-14]. Initially in China, there chest tightness or palpitations were seen. 38 Gradually in March 2020, loss of smell was seen [15]. At last the disease may progress to pneumonia, multi-organ failure, and death [16,17].

\section{Current world scenario}

Till $28^{\text {th }}$ May 2020, total 5,592,890 people were affected by this deadly virus and there were 353,321 death cases according to WHO.

\section{India scenario}

According to Worldometer, total 165,799 COVID-19 cases were found till $29^{\text {th }}$ May 2020 and total number of death cases was 4,711.

\section{Prevention}

The preventive measures which include: staying at home, avoiding crowded places, washing hands with soap and warm water often for 20 seconds, avoiding touching eyes, nose, mouth with unwashed hands [18-20]. According to the CDC it was recommended that mouth and nose should be covered with a tissue when coughing or sneezing. In case of unavailability of tissue, inside of the elbow can be used [18]. Closing the crowded organizations like schools, offices, etc. is the medium of social distance for which healthy people cannot be closely with the infected people [21]. Social distancing includes 6 feet apart (about 1.80 meters) [22]. According to WHO, the use of masks is recommended only for the person who is coughing or sneezing or who is taking care of a suspected person [23]. But some countries recommend wearing for masks for healthy individuals particularly China [24], Hong Kong [25] and Thialand [26]. Some health experts also recommend to use scarve or bandanas for covering face in case of unavailability of masks as they also can prevent from direct contact with the coughs or sneezes from an infected person [27]. According to CDC it is advised that COVID-19 persons should stay at home in isolation. They should not share any personal household items with anyone; should wash their hands with soap and water regularly; cover their face with tissue while sneezing or coughing and cover their face with mask while visiting with another person to the hospital or even inside the office of the healthcare provider [28,29]. CDC also recommends to use hand sanitizer with at least $60 \%$ alcohol when soap and water are not available [18]. It is always better to wear eye glasses for protection of eyes so that by chance it is not touched by hand.

\section{Personal protective equipment's}

According to CDC, the personal protective equipment's include: respirator or facemask [30,31], gown, medical gloves [32], eye protection [33].

Points for increasing immunity power to fight against corona virus

\section{Essential foods for boosting our immunity system}

Citrus fruits, garlic, broccoli and spinach enhance our immunity power. Those who have weak immunity system can take the supplements of vitamin-C, B, D and Zinc. According to high quality evidence it was found that vitamin-C supplementation $(\geq 0.2 \mathrm{~g} /$ day or therapeutic doses of $4-8 \mathrm{~g} /$ day) in adults and children with a common cold can significantly reduce its duration [34,35].

Low to moderate evidence showed that there may be potential benefits of supplementary vitamin-D in adults and children with tuberculosis, influenza or upper RTI [36]. The composition of intestinal microbiota is affected by vitamins D, A, B6, and B12 and folate [37].

Vitamin-C destroys free radicals and supports the body immunity response. Vitamin-C rich foods are like raw apples, carrots, lemons, oranges, broccoli, bell peppers, kiwi, papaya, sweet potato, garlic etc

Zinc helps in maintaining body's ability to make new cells and enzymes, process carbohydrate, fat and protein and increases the speed of healing muscles and wounds. According to some evidences, zinc is helpful in the prevention of colds, viruses and minimizes symptoms of allergy. Red meats, shellfish and eggs are high in Zinc. For vegetarians, nuts, whole grains and legumes (chickpeas, lentils, beans) are helpful.

Nutritious vegetables like mushrooms, spinach, broccoli, kale, and garlic contain zinc, as well as other vital vitamins and miner- 
als. Per cup of raw veggies, mushrooms and kale both contain 2 percent $(0.4 \mathrm{mg})$ of the daily value of zinc. Zinc supplementation enhances the immunity power. It can prevent diarrhea and respiratory problems [38]. These can be a trail mix of walnuts, almonds, cashews and other dry fruits and nuts. - Another way to add zinc to your daily diet would be to turn to seeds, especially sunflower seeds, pumpkin seeds, watermelon seeds and sesame seeds these are enriched with zinc. Our elders in old time used to use these pumpkin seeds and watermelon seeds and sesame seeds in their daily diet.

Fermented foods are helpful for the immunity system as they increase good bacteria in gut. Examples of fermented foods are: idli, dhokla, yogurt, kanji, lassi etc. Dairy products like fermented milk and skimmed yogurt made from unpasteurized milk help in fermentation of undigested plant fibers and through blood stream make them improving immunity system [39].

Ginger helps in improving the defensive responses in the upper respiratory tract and digestive mucosa. It can fight against infections like bacterial and viral such as colds, flu, chest infections and sore throats. Ginger can help with digestion and constipation. It has anti-microbial potential which can treat infectious diseases [40].

Garlic is rich in vitamin- $\mathrm{B}_{6}$ and $\mathrm{C}$, selenium, fiber and immune boosting compounds. It is anti-viral and anti-fungal in nature. One can include use of garlic in food items. In many states curries are made where ginger and garlic are used. Substantial studies have shown that garlic and its bioactive constituents exhibit antioxidant, anti-inflammatory, antibacterial, antifungal, immunomodulatory, cardiovascular protective, anticancer, hepatoprotective, digestive system protective, anti-diabetic, anti-obesity, neuroprotective, and renal protective properties [41].

Beta glucan which is a soluble fiber comes from yeasts improves immunity power. It is profitable in case of asthma, allergies, Crohn's disease etc. $\beta$-Glucan is a nonstarch polysaccharide having documented health benefits and industrial applications. It can be extracted from various sources, including cereals, bacteria, molds, and fungi. Documented health benefits make $\beta$-glucan a potential candidate for food product development having nutraceutical status. Bakery products, dairy products, meat products, and beverage products contain $\beta$-glucan, which can be taken to boost the immunity system [42]. Similarly, Mushrooms are high in beta glucans are helpful for better immunity system.

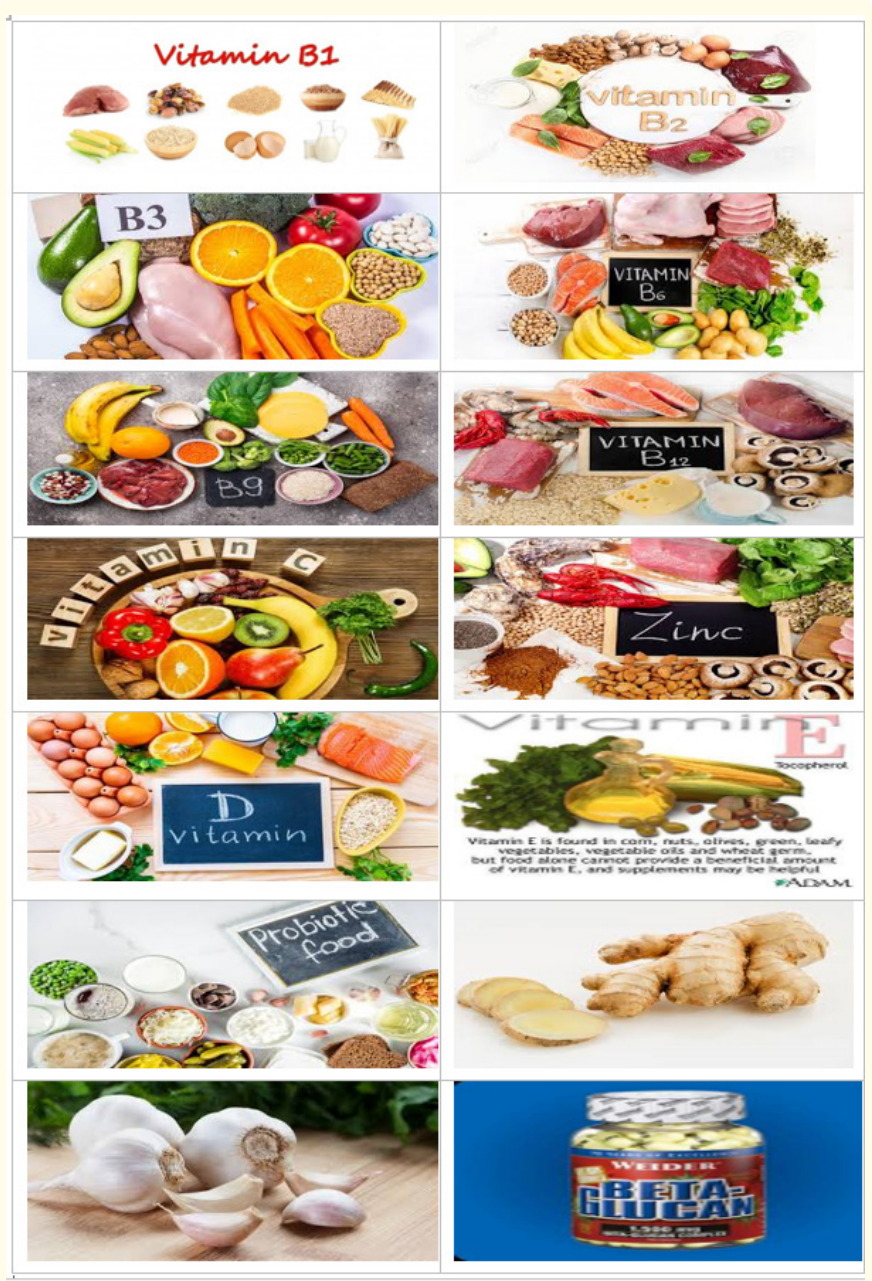

Figure 1: Immunity enhancing food.

\begin{tabular}{|l|c|}
\hline \multicolumn{1}{|c|}{ Nutrients } & Recommendation (for adults) \\
\hline Vitamin-B1 & $1.0-1.7 \mathrm{mg} /$ day \\
\hline Vitamin-B2 & $1.1-2.1 \mathrm{mg} /$ day \\
\hline Vitamin-B3 & $14-21 \mathrm{mg} /$ day \\
\hline Vitamin-B6 & $2.0 \mathrm{mg} /$ day \\
\hline Vitamin-B9 & $200 \mu \mathrm{g} /$ day \\
\hline Vitamin-B12 & $1.0 \mu \mathrm{g} /$ day \\
\hline Vitamin-C & $40 \mathrm{mg} /$ day \\
\hline Zinc & $10-12 \mathrm{mg} /$ day \\
\hline
\end{tabular}

Table 2: Nutrients and their doses. 
Inflammation should be reduced by removing the inflammatory foods from diet like sugar, processed meat, vegetable oils and alcohol. Mycotoxins from mold are responsible for destroying immunity. Chlorinated drinking, chlorinated water, pesticides, aromatic hydrocarbons, heavy metals, air pollution and food additives should be minimized.

\section{Conclusion}

In this report covid-19 and it causes, symptoms, as well as preventions have been discussed. Particularly data on different types of healthy immunity boosting nutritious foods along with vitamins and minerals towards one's immunity power has been described in detail which will be helpful in preventing the infection of covid-19.

\section{Acknowledgement}

Authors would like to thank the president of SOA University for kindly allowing us to publish this paper.

\section{Bibliography}

1. Kahn Jeffrey and McIntosh Kenneth. "History and recent advances in coronavirus discovery". Pediatric Infectious Disease Journal 24.11 (2005): s223-s227.

2. Geller C., et al. "Human coronaviruses: insights into environmental resistance and its influence on the development of new antiseptic strategies". Viruses 4.11 (2012): 3044-3068.

3. There is also a characteristic "fringe" of projections $200 \mathrm{~A}$ long, which are rounded or petal shaped ... This appearance, recalling the solar corona, is shared by mouse hepatitis virus and several viruses recently recovered from man, namely strain B814, 229E and several others. "Virology: Coronaviruses". Nature 220.5168(1968): 650-650.

4. Sturman Lawrence S., et al. These viruses displayed a characteristic fringe of large, distinctive, petal-shaped peplomers or spikes which resembled a crown, like the corona spinarum in religious art; hence the name coronaviruses. "The Molecular Biology of Coronaviruses". Advances in Virus Research 28 (1983): 35-112.

5. Gu Jinyang., et al. "COVID-19: Gastrointestinal manifestations and potential fecal-oral transmission". Gastroenterology (2020).
6. Zhan Wei., et al. "Molecular and serological investigation of 2019-nCoV infected patients: implication of multiple shedding routes". Emerging Microbes and Infections 9.1 (2020): 386-389.

7. Shu-Ming Duan., et al. Biomedical and Environmental Sciences 16.3(2003): 246-255.

8. “Coronavirus Disease 2019 (COVID-19) Symptoms”. Centers for Disease Control and Prevention. United States (2020).

9. Chen N., et al. "Epidemiological and clinical characteristics of 99 cases of 2019 novel coronavirus pneumonia in Wuhan, China: a descriptive study". Lancet 395.10223(2020): 507-513.

10. Hessen MT. "Novel Coronavirus Information Center: Expert guidance and commentary". Elsevier Connect (2020).

11. “Coronavirus Disease 2019 (COVID-19)-Symptoms". Centers for Disease Control and Prevention. 20 March 2020 (2020).

12. Wei Xiao-Shan., et al. "Clinical Characteristics of SARS-CoV-2 Infected Pneumonia with Diarrhea". Rochester, NY. SSRN 3546120 (2020).

13. Huang C., et al. "Clinical features of patients infected with 2019 novel coronavirus in Wuhan, China". Lancet 395.10223(2020): 497-506.

14. Lai Chih-Cheng., et al. "Severe acute respiratory syndrome coronavirus 2 (SARS-CoV-2) and coronavirus disease-2019 (COVID-19): The epidemic and the challenges". International Journal of Antimicrobial Agents 55 (2020).

15. Zheng YY., et al. "COVID-19 and the cardiovascular system". Nature Reviews Cardiology 115.31(2020): 1-8.

16. Hui DS., et al. "The continuing 2019-nCoV epidemic threat of novel coronaviruses to global health-The latest 2019 novel coronavirus outbreak in Wuhan, China". International Journal of Infectious Diseases 91(2020): 264-66.

17. “Q\&A on coronaviruses". World Health Organization (WHO). Archived from the original on 20 January (2020).

18. Centers for Disease Control (3 February 2020). "Coronavirus Disease 2019 (COVID-19): Prevention and Treatment”. Archived from the original on 15 December (2019). 
19. World Health Organization. "Advice for Public" (2020).

20. "My Hand-Washing Song: Readers Offer Lyrics For A 20-Second Scrub". NPR.org. (2020).

21. Maragakis LL. "Coronavirus, Social Distancing and Self Quarantine". John Hopkins University. 18 March. www.hopkinsmedicine.org.

22. Parker-Pope Tara. "Deciding How Much Distance You Should Keep". The New York Times (2020).

23. "When and how to use masks". World Health Organization (WHO) (2020).

24. "For different groups of people: how to choose masks". NHC. gov.cn. National Health Commission of the People's Republic of China. 7 February 2020. Disposable medical masks: Recommended for: People in crowded places. Indoor working environment with a relatively dense population. People going to medical institutions . Children in kindergarten and students at school gathering to study and do other activities.

25. “Prevention of Coronavirus Disease 2019 (COVID-19)” (PDF). Centre for Health Protection. Wear a surgical mask when taking public transport or staying in crowded place (2020).

26. Kuhakan Jiraporn."Better than nothing': Thailand encourages cloth masks amid surgical mask shortage". Reuters. Thailand's health authorities are encouraging people to make cloth face masks at home to guard against the spread of the coronavirus amid a shortage of surgical masks. The droplet from coughing and sneezing is around five microns and we have tested already that cloth masks can protect against droplets bigger than one micron (2020).

27. "Guidance against wearing masks for the coronavirus is wrong - you should cover your face - The Boston Globe". (2020).

28. "Coronavirus Disease 2019 (COVID-19)—Prevention and Treatment". Centers for Disease Control and Prevention. U.S. Department of Health and Human Services (2020).

29. Centers for Disease Control and Prevention. "What to do if you are sick with 2019 Novel Coronavirus (2019-nCoV)" (2020).

30. Filtering out Confusion: Frequently Asked Questions about Respiratory Protection, User Seal Check. The National Institute for Occupational Safety and Health (2018).

31. Proper N95 Respirator Use for Respiratory Protection Preparedness. NIOSH Science Blog (2020).

32. “Coronavirus Disease 2019 (COVID-19)". Centers for Disease Control and Prevention (2020).
33. "Strategies for Optimizing the Supply of Eye Protection". CDC (2020).

34. Hemilä H and Chalker E. "Vitamin C for preventing and treating the common cold". Cochrane Database System Review 1(2013).

35. Ran L., et al. "Extra dose of vitamin C based on a daily supplementation shortens the common cold: A meta-analysis of 9 randomized controlled trials". BioMed Research International (2018).

36. Yamshchikov AV., et al. "Vitamin D for treatment and prevention of infectious diseases: A systematic review of randomized controlled trials". Endocrine Practice 15(2009) 438-449.

37. Gombart FA., et al. "A Review of Micronutrients and the Immune System-Working in Harmony to Reduce the Risk of Infection". Nutrients 12.1(2020).

38. Penny EM. "Zinc supplementation as adjunct therapy in diarrhea has been shown to be efficacious with a potential to reduce morbidity and mortality especially among populations with a high burden of zinc deficiency". Annals of Nutrition and Metabolism 62.1(2013):31-42.

39. Conlon M and Bird A. "The impact of diet and lifestyle on gut microbiota and human health". Nutrients 7.1(2015): 17-44.

40. Mashhadi SN., et al. "Anti-Oxidative and Anti-Inflammatory Effects of Ginger in Health and Physical Activity: Review of Current Evidence". International Journal of Preventive Medicine 4.1(2013): 36-42.

41. Shang A., et al. "Bioactive Compounds and Biological Functions of Garlic (Allium sativum L.)”. Foods Journal 8.7 (2019): 1-31.

42. Asif Ahmad and Muhammad Kaleem. Biopolymers for Food Design (2018): 351-381.

\section{Assets from publication with us}

- Prompt Acknowledgement after receiving the article

- Thorough Double blinded peer review

- Rapid Publication

- Issue of Publication Certificate

- High visibility of your Published work

Website: $\underline{w w w . a c t a s c i e n t i f i c . c o m / ~}$

Submit Article: www.actascientific.com/submission.php Email us: editor@actascientific.com

Contact us: +919182824667 